\title{
HUBUNGAN PENGETAHUAN IBU DAN EKONOMI KELUARGA DENGAN TUMBUH KEMBANG BALITA DI DESA GEUDONG GEUDONG KECAMATAN KOTA JUANG KABUPATEN BIREUEN TAHUN 2019
}

\section{Relationship Between Mother And Economic Knowledge With Growth Of Children In The Village Of Geudong Geudong Kecamatan Kota Juang Kabupaten Bireuen In 2019}

\author{
Misrina*1, Yossi Risnika*2 $^{* 2}$ \\ 1. Dosen Akademi Kebidanan Munawarah, Jl. Sultan Iskandar Muda No.18 Kota Juang, Bireuen 24251, Indonesia \\ 2. Mahasiswi Akademi Kebidanan Munawarah, Jl. Sultan Iskandar Muda No.18 Kota Juang, Bireuen 24251, \\ Indonesia
}

*Korespondensi Penulis : misrina517@ gmail.com*1

\begin{abstract}
Abstrak
Proses tumbuh kembang anak merupakan proses yang berkesinambungan mulai dari lahir sampai dewasa. Ini berarti bahwa tumbuh kembang anak merupakan suatu tahapan proses yang harus dilalui oleh setiap anak. Anak yang sehat akan menunjukkan tumbuh kembang yang optimal, sesuai dengan anak lain seusianya dan juga sesuai dengan parameter baku perkembangan anak.

Penelitian ini dilakukan untuk melihat ada hubungan pengetahuan ibu dan ekonomi keluarga dengan tumbuh kembang balita di Desa Geudong geudong Kecamatan Kota Juang Kabupaten Bireuen Tahun 2019.

Desain penelitian yang digunakan adalah penelitian analitik dengan pendekatan cross sectional. Penelitian ini telah dilaksanakan di di Desa Geudong geudong Kecamatan Kota Juang Kabupaten Bireuen pada tanggal 22 sampai 26 Mei 2019. Sampel sebanyak 202 responden yang diperoleh dengan cara random sampling.

Hasil penelitian yang dilakukan terhadap 202 responden dengan judul "Hubungan Pengetahuan ibu dan Ekonomi Keluarga dengan Tumbuh Kembang Balita di Desa Geudong Geudong Kecamatan Kota Juang Kabupaten Bireuen, menunjukkan Ada hubungan pengetahuan ibu dengan pertumbuhan balita ditunjukkan dengan nilai $\mathrm{p}(0,018)$. Tidak ada hubungan pengetahuan ibu dengan perkembangan balita ditunjukkan dengan nilai $p(0,230)$. Ada hubungan ekonomi keluarga dengan pertumbuhan balita ditunjukkan dengan nilai $\mathrm{p}$ $(0,010)$. Ada hubungan ekonomi keluarga dengan perkembangan balita ditunjukkan dengan nilai $\mathrm{p}(0,001)$.

Dari tahap pertumbuhan balita, variabel pengetahuan ibu ada hubungannya akan tetapi dari variabel status ekonomi keluarga tidak ada hubungannya sedangkan pada tahap perkembangan balita, pengetahuan ibu tidak ada hubungannya tetapi dari status ekonomi keluarga ada hubungannya.
\end{abstract}


Journal of Healthcare Technology and Medicine Vol. 5 No. 2 Oktober 2019

Universitas Ubudiyah Indonesia

e-ISSN : 2615-109X

\section{ABSTRACT}

The child's growth and development process is a continuous process from birth to adulthood. This means that the child's growth and development is a stage of the process that must be passed by every child. A healthy child will show optimal growth and development, in accordance with other children his age and also in accordance with the standard parameters of child development.

This study was conducted to see the relationship between mother's knowledge and family economy with the development of toddlers in Geudong Geudong Village, Juang City District, Bireuen Regency in 2019.

The research design used was analytic research with cross sectional approach. This research has been carried out in Geudong Geudong Village, Juang City District, Bireuen Regency on 22 to 26 May 2019. Samples of 202 respondents were obtained by random sampling.

The results of a study of 202 respondents with the title "Relationship between Mother Knowledge and Family Economy with Growth and Development of Toddlers in Geudong Geudong Village, Juang City District, Bireuen District, showed that there was a relationship between mother's knowledge and the growth of children under five, indicated by the $p$ value (0.018). There is no relationship between mother's knowledge and the development of children under five, indicated by $p$ value (0.230). There is a family economic relationship with the growth of children under five, indicated by the value of $p$ (0.010). There is a family economic relationship with the development of children under five indicated by the value of $p$ (0.001).

From the toddler's growth stage, the mother's knowledge variable has something to do but from the family's economic status variable has nothing to do while at the toddler's development stage, mother's knowledge has nothing to do but from the family's economic status has to do.

\section{Keywords: Knowledge, Economy, Growth and development}

\section{PENDAHULUAN}

Anak merupakan aset dan generasi penerus sebuah bangsa, sehingga penting untuk membentuk pribadi anak yang berkualitas. Kualitas seorang anak dapat dilihat dari tumbuh kembangnya. Namun hingga saat ini, keterlambatan tumbuh kembang pada anak masih menjadi masalah serius di negara maju maupun negara berkembang di dunia. Penelitian sebelumnya menyebutkan, anak-anak di 54 negara maju yang menunjukkan beberapa gejala gangguan perilaku anti sosial yang dapat berkembang menjadi gangguan perilaku di kemudian hari (Suryani, 2016 dikutip dari Firdaus, 2018).

Proses tumbuh kembang anak merupakan proses yang berkesinambungan mulai dari lahir sampai dewasa, ini berarti bahwa tumbuh kembang anak merupakan suatu tahapan proses yang harus dilalui oleh setiap anak. Anak yang sehat akan menunjukkan tumbuh 
Journal of Healthcare Technology and Medicine Vol. 5 No. 2 Oktober 2019

Universitas Ubudiyah Indonesia

e-ISSN : 2615-109X

kembang yang optimal, sesuai dengan anak lain seusianya dan juga sesuai dengan parameter baku perkembangan anak (Maryunani, 2012).

Pertumbuhan dan perkembangan anak terdapat dua peristiwa, yaitu peristiwa percepatan dan perlambatan. Peristiwa tersebut akan berlainan dalam satu organ tubuh. Peristiwa percepatan dan perlambatan tersebut merupakan suatu kejadian yang berbeda dalam setiap organ tubuh, namun masing saling berhubungan satu dengan yang lain. Misalnya terjadi perubahan tentang besarnya, jumlah dan ukuran ditingkat sel maupun organ pada individu serta perubahan bentuk dan fungsi pematangan organ mulai dari aspek sosial, emosional dan intelektual (Hidayat, 2009).

Lima tahun pertama kehidupan merupakan masa yang sangat peka terhadap pengaruh lingkungan baik biologis, fisik, maupun sosial. Balita adalah anak yang telah menginjak usia di atas satu tahun atau lebih popular dengan pengertian usia anak di bawah lima tahun (Sutomo, 2010 dikutip dari Amelia, 2018).

Perkembangan anak melewati perkembangan fase awal meliputi beberapa aspek kemampuan fungsional, yaitu kognitif, psikomotorik, sosial, dan bahasa. Perkembangan psikomotorik merupakan aspek perkembangan yang penting karena berkaitan dan mendorong aspek perkembangan lain. Pada masa balita mengalami kecepatan pertumbuhan menurun, sedangkan dalam perkembangan psikomotorik (motorik kasar dan motorik halus) mengalami kemajuan. Dimulai dengan gerak kasar yang berhubungan dengan kemampuan anak melakukan pergerakan dan sikap tubuh yang melibatkan otot-otot besar seperti duduk, berdiri, dan sebagainya. Kemudian dilanjutkan dengan gerak halus yang berhubungan dengan kemampuan anak melakukan gerakan yang melibatkan bagian-bagian tubuh tertentu dan dilakukan oleh otot-otot kecil, tetapi memerlukan koordinasi yang cermat seperti mengamati sesuatu, memegang, menulis, dan sebagainya (Kemenkes, 2012 dikutip dari Amelia, 2018).

Angka kejadian keterlambatan perkembangan anak di Amerika Serikat berkisar 1216\%, Argentina 22\%, dan Hongkong 23\%. Fenomena ini juga terjadi di Kanada dan Selandia Baru, dimana terdapat 5-7\% anak yang mengalami gangguan perkembangan sosial. Sementara itu, gangguan perkembangan pada anak di Thailand mencapai 37,1\% dan di India berkisar 19,8\% (Firdaus, 2018).

Data di Indonesia, balita yang ditimbang sesuai standar ( $>8$ kali dalam 12 bulan terakhir) sebesar $54,6 \%$, dan yang ditimbang tidak sesuai standar ( $\$ 8$ kali dalam 12 bulan terakhir) sebesar 40\%. Proporsi pengukuran panjang atau tinggi badan $\geq 2$ kali dalam 12 bulan terakhir pada balita sebesar 77,8\% (RISKESDAS, 2018). 
Journal of Healthcare Technology and Medicine Vol. 5 No. 2 Oktober 2019

Universitas Ubudiyah Indonesia

e-ISSN : 2615-109X

Di Provinsi Aceh, Proporsi pengukuran panjang atau tinggi badan $\geq 2$ kali dalam 12 bulan terakhir pada balita sekitar 76\%. Proporsi gizi buruk dan gizi kurang $24 \%$. Sedangkan status gizi sangat pendek dan gizi pendek $31 \%$ (RISKESDAS, 2018).

Tumbuh kembang dikatakan terlambat jika seorang anak tidak mencapai tahap pertumbuhan dan perkembangan yang diharapkan pada umur yang semestinya, dengan ketertinggalan dalam populasi yang normal. Prevalensi keterlambatan di suatu populasi sangat bervariasi, studi yang dilakukan Dudley mencatat 3,3\%-17\% anak mengalami keterlambatan (Kusuma, 2012).

Seiring dengan perkembangan psikomotorik ini, pada balita usia pra-sekolah (3-5 tahun), tepat sekali diajarkan dan dilatihkan perkembangan psikomotorik sesuai dengan umurnya serta pemantauan perkembangan. Implikasi perkembangan psikomotorik ini, di Taman Kanak-Kanak (TK) sudah dirancangnya sebagai lingkungan pendidikan yang kondusif bagi perkembangan psikomotorik anak secara optimal (Sutomo 2010, dikutip dari Amelia, 2018).

Keluarga sebagai lingkungan sosial pertama yang dikenal anak memiliki peran penting dalam proses perkembangan sosial anak. Dalam hal ini, perlu diperhatikan keadaan sosioekonomi, tingkat kecerdasan dan pengetahuan, tingkat pendidikan orang tua, pola asuh, serta nutrisi yang diberikan kepada anak. WHO menyatakan kemampuan orang tua untuk mendeteksi tumbuh kembang anak dipengaruhi oleh tingkat pengetahuan dan tingkat pendidikan. Namun, penelitian lain yang menganalisis pengaruh tingkat pendidikan terhadap perkembangan sosial anak balita menyatakan bahwa pengaruh tingkat pendidikan tidak signifikan mempengaruhi perkembangan sosial anak balita (Supariasa, 2012 dikutip dari Firdaus, 2018).

Kebutuhan dasar untuk tumbuh kembang anak terutama dicukupi oleh ibu, ayah, anggota keluarga serta lingkungan sekitar. Upaya mencukupi kebutuhan-kebutuhan dasar tersebut dilakukan melalui interaksi yang adekuat, terus menerus, sesuai dengan tahapan umur. Semakin erat dan semakin sering faktor di lingkungan tersebut berinteraksi dengan anak, maka faktor tersebut semakin besar peranannya dalam menentukan kualitas tumbuh kembang anak (Kusuma, 2012).

Proses tumbuh kembang bayi dan balita merupakan masa yang penting dalam perkembangan selanjutnya. Peran keluarga dalam bidang kesehatan dan dukungan sosial, ekonomi berkontribusi bagi balita dalam menjalani proses tumbuh kembang secara normal dan wajar sehingga tidak ada penyimpangan (Mulyono, 2014). 
Journal of Healthcare Technology and Medicine Vol. 5 No. 2 Oktober 2019

Universitas Ubudiyah Indonesia

e-ISSN : 2615-109X

Orang tua wajib membina dan memelihara pertumbuhan dan perkembangan anak yang dilaluinya, sehingga pada suatu saat anak mampu bertindak dan berfungsi dengan baik (Hasballah, 2009).

Jumlah balita di Kabupaten Bireuen yang dilaporkan sebanyak 45.823 jiwa. Sedangkan jumlah balita yang ditimbang sebanyak 29.081 jiwa. Jumlah balita terbanyak yaitu di Wilayah Kerja Puskesmas Kota Juang sebanyak 5.380 jiwa. (Dinkes Bireuen, 2018).

Berdasarkan hasil survey awal yang peneliti lakukan di Desa Geudong geudong Kecamatan Kota Juang Kabupaten Bireuen, dari 10 ibu yang diwawancarai 7 dari mereka hanya mengetahui pertumbuhan anak mereka dipantau dari berat badan saja, namun untuk perkembangan anak mereka tidak memahaminya, sedangkan 3 ibu sudah tahu tentang pertumbuhan dan perkembangan yang terjadi pada balita, dilihat dari sudut ekonomi 6 dari ibu memiliki taraf ekonomi rendah, sementara 3 menengah dan 1 ibu memiliki taraf ekonomi tinggi.

Berdasarkan latar belakang diatas, maka peneliti tertarik untuk meneliti tentang "Hubungan pengetahuan ibu dan ekonomi keluarga dengan tumbuh kembang balita di Desa Geudong geudong Kecamatan Kota Juang Kabupaten Bireuen”.

Tujuan penelitian ini untuk mengetahui hubungan pengetahuan ibu dan ekonomi keluarga dengan tumbuh kembang balita di Desa Geudong geudong Kecamatan Kota Juang Kabupaten Bireuen Tahun 2019.

Penelitian ini diharapkan Sebagai bahan informasi dan masukan kepada responden agar lebih memahami lagi masalah pertumbuhan serta perkambangan yang terjadi pada balita.

\section{METODE PENELITIAN}

Desain penelitian yang digunakan adalah penelitian analitik dengan pendekatan cross sectional, yaitu penelitian yang dilakukan dengan tujuan utama untuk menjawab permasalahan yang sedang dihadapi pada situasi seseorang untuk melihat bagaimana hubungan pengetahuan ibu dan ekonomi keluarga dengan tumbuh kembang balita di Desa Geudong geudong Kecamatan Kota Juang Kabupaten Bireuen Tahun 2019.

Penelitian ini telah dilakukan di Penelitian ini telah dilakukan di Desa Geudong geudong Kecamatan Kota Juang Kabupaten Bireuen. Penelitian ini telah dilaksanakan pada tanggal 22 sampai 26 Mei 2019.

Populasi dalam penelitian ini adalah seluruh ibu yang memiliki balita di Desa Geudong geudong Kecamatan Kota Juang Kabupaten Bireuen sebanyak 407 balita. 
Journal of Healthcare Technology and Medicine Vol. 5 No. 2 Oktober 2019

Universitas Ubudiyah Indonesia

e-ISSN : 2615-109X

Pengambilan sampel diambil secara random sampling dengan menggunakan rumus slovin.

Jenis data yang digunakan dalam penelitian ini adalah data primer dan data sekunder. Metode pengelohan data collecting, checking, coding, entering dan processing. Analisis data yang digunakan adalah analisis univariat dan analisis bivariat dengan uji chi-square.

\section{HASIL PENELITIAN}

Analisis Bivariat digunakan untuk mengetahui hubungan antara pengetahuan dan ekonomi keluarga dengan pertumbuhan dan perkembangan balita.

Tabel 1. Tabulasi Silang Hubungan Pengetahuan Ibu dan Ekonomi Keluarga Dengan Tumbuh Kembang Balita Di Desa Geudong Geudong Kecamatan Kota Juang Kabupaten Bireuen Tahun 2019.

\begin{tabular}{|c|c|c|c|c|c|c|c|c|c|c|c|}
\hline \multirow{3}{*}{$\begin{array}{l}\text { Pengetahuan } \\
\text { Ibu }\end{array}$} & \multicolumn{8}{|c|}{ Pertumbuhan } & \multirow[t]{2}{*}{$\sum$} & \multirow[t]{2}{*}{$\%$} & \multirow[t]{3}{*}{ P-Value } \\
\hline & \multicolumn{2}{|c|}{ Normal } & \multicolumn{2}{|c|}{ Kurus } & \multicolumn{2}{|c|}{$\begin{array}{c}\text { Sangat } \\
\text { kurus }\end{array}$} & \multicolumn{2}{|c|}{ Gemuk } & & & \\
\hline & $\mathrm{f}$ & $\%$ & $\mathrm{f}$ & $\%$ & $\mathrm{f}$ & $\%$ & $\mathrm{f}$ & $\%$ & $\mathrm{~F}$ & $\%$ & \\
\hline Baik & 44 & 22,5 & 1 & 0,5 & 0 & 0 & 2 & 1 & 47 & 23 & \\
\hline Cukup & 116 & 57 & 2 & 1 & 0 & 0 & 0 & 0 & 118 & 59 & 0,018 \\
\hline Kurang & 33 & 16 & 3 & 1,5 & 1 & 0,5 & 0 & 0 & 37 & 18 & \\
\hline \multirow{3}{*}{$\begin{array}{l}\text { Pengetahuan } \\
\text { Ibu }\end{array}$} & \multicolumn{8}{|c|}{ Perkembangan } & $\sum$ & $\%$ & P-Value \\
\hline & \multicolumn{4}{|c|}{ Tidak Terhambat } & \multicolumn{4}{|c|}{ Terhambat } & & & \\
\hline & \multicolumn{2}{|c|}{$\mathrm{F}$} & \multicolumn{2}{|c|}{$\%$} & \multicolumn{2}{|c|}{$\mathrm{f}$} & \multicolumn{2}{|c|}{$\%$} & $\mathrm{~F}$ & $\%$ & \\
\hline Baik & \multicolumn{2}{|c|}{46} & \multicolumn{2}{|c|}{22,5} & \multicolumn{2}{|c|}{1} & \multicolumn{2}{|c|}{0,5} & 47 & 23 & \\
\hline Cukup & \multicolumn{2}{|c|}{115} & \multicolumn{2}{|c|}{57} & \multicolumn{2}{|c|}{3} & \multicolumn{2}{|c|}{1,5} & 118 & 59 & 0,23 \\
\hline Kurang & \multicolumn{2}{|c|}{34} & \multicolumn{2}{|c|}{17} & \multicolumn{2}{|c|}{3} & \multicolumn{2}{|c|}{1,5} & 37 & 18 & \\
\hline \multirow{3}{*}{$\begin{array}{l}\text { Ekonomi } \\
\text { Keluarga }\end{array}$} & \multicolumn{8}{|c|}{ Pertumbuhan } & $\sum$ & $\%$ & P-Value \\
\hline & & & & us & $\begin{array}{r}\text { Sal } \\
\text { ku }\end{array}$ & $\begin{array}{l}\text { igat } \\
\text { rus }\end{array}$ & & nuk & & & \\
\hline & $\mathrm{f}$ & $\%$ & $\mathrm{f}$ & $\%$ & $\mathrm{f}$ & $\%$ & $\mathrm{f}$ & $\%$ & $\mathrm{~F}$ & $\%$ & \\
\hline Tinggi & 49 & 24 & 2 & 1 & 0 & 0 & 1 & 0,5 & 52 & 26 & \\
\hline Menengah & 143 & 71 & 3 & 1,5 & 1 & 0,5 & 1 & 0,5 & 148 & 73 & 0,01 \\
\hline Rendah & 1 & 0,5 & 1 & 0,5 & 0 & 0 & 0 & 0 & 2 & 1 & \\
\hline Ekonomi & & & Pel & remb & nga & & & & $\sum$ & $\%$ & P-Value \\
\hline & & k terh & $\mathbf{m b}$ & & & Terh & nb: & & & & \\
\hline & & & & & & E & & & $\mathrm{F}$ & $\%$ & \\
\hline Tinggi & & & & & & 2 & & & 52 & 26 & 0,001 \\
\hline Menengah & & & & & & $t$ & & 5 & 148 & 73 & \\
\hline Rendah & & & & & & 2 & & 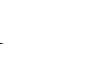 & 2 & 1 & \\
\hline
\end{tabular}


Journal of Healthcare Technology and Medicine Vol. 5 No. 2 Oktober 2019

Universitas Ubudiyah Indonesia

e-ISSN : 2615-109X

Analisis Bivariat : Tabel 1 dapat dilihat tabulasi silang terhadap pengetahuan ibu dengan pertumbuhan balita, dari 202 responden mayoritas yang memiliki balita dengan pertumbuhan normal sebanyak 193 responden (95,5\%), terdiri dari responden yang memiliki pengetahuan baik 44 responden (22,5\%), pengetahuan cukup 116 responden (57\%) dan pengetahuan kurang 33 responden (16\%).

Dari hasil uji chi square dengan tingkat kepercayaan $95 \%(\alpha=0,05)$ hasil perhitungan menunjukkan nilai $\mathrm{p}(0,018)<\mathrm{p}$ value $(0,05)$ berarti ada hubungan pengetahuan ibu dengan pertumbuhan pada balita.

Berdasarkan uji silang pengetahuan ibu dengan perkembangan balita, dari 202 responden mayoritas memiliki balita dengan perkembangan tidak terhambat sebanyak 195 responden (96,5\%), yang terdiri dari responden yang memiliki pengetahuan baik 46 responden $(22,5 \%)$, pengetahuan cukup 115 responden $(57 \%)$ dan pengetahuan kurang 34 responden $(17 \%)$.

Dari hasil uji chi square dengan tingkat kepercayaan 95\% $(\alpha=0,05)$ hasil perhitungan menunjukkan nilai $\mathrm{p}(0,230)>\mathrm{p}$ value $(0,05)$ berarti tidak ada hubungan antara pengetahuan ibu dengan perkembangan pada balita.

Tabel 2 dapat dilihat dari tabulasi silang ekonomi keluarga ibu dengan Pertumbuhan balita, dari 202 responden mayoritas responden memiliki balita dengan pertumbuhan normal sebanyak 193 responden $(95,5 \%)$, yang terdiri dari ibu dengan ekonomi keluarga tinggi 49 responden (24\%), ekonomi mennengah 143 responden (71\%) dan ekonomi rendah 1 responden $(0,5 \%)$.

Dari hasil uji chi square dengan tingkat kepercayaan 95\% $(\alpha=0,05)$ hasil perhitungan menunjukkan nilai $\mathrm{p}(0,010)<\mathrm{p}$ value $(0,05)$ berarti ada hubungan antara ekonomi dengan pertumbuhan balita.

Berdasarkan uji silang ekonomi keluarga ibu dengan perkembangan balita, dari 202 responden mayoritas responden memiliki balita dengan perkembangan tidak terhambat sebanyak 195 responden (96,5\%), yang terdiri dari ibu yang memiliki ekonomi tinggi 50 responden (25\%), ekonomi menengah 144 responden (71\%) dan rendah 1 responden $(0,5 \%)$.

Dari hasil uji chi square dengan tingkat kepercayaan 95\% $(\alpha=0,05)$ hasil perhitungan menunjukkan nilai $\mathrm{p}(0,001)<\mathrm{p}$ value $(0,05)$ berarti ada hubungan antara ekonomi dengan perkembangan pada balita.

\section{PEMBAHASAN}


Journal of Healthcare Technology and Medicine Vol. 5 No. 2 Oktober 2019

Universitas Ubudiyah Indonesia

e-ISSN : 2615-109X

Hubungan Pengetahuan Ibu Dengan Pertumbuhan Balita : Dari hasil penelitian, didapatkan pengetahuan responden dalam kategori cukup sebanyak 118 responden (59\%). Sedangkan pertumbuhan balita berada dalam kategori normal sebanyak 193 responden (95,5\%). Berdasarkan uji silang dari 202 responden, mayoritas yang memiliki balita dengan pertumbuhan normal sebanyak 193 responden $(95,5 \%)$, terdiri dari responden yang memiliki pengetahuan baik 44 responden (22,5\%), pengetahuan cukup 116 responden (57\%) dan pengetahuan kurang 33 responden (16\%).

Dari hasil uji chi square dengan tingkat kepercayaan 95\% $(\alpha=0,05)$ hasil perhitungan menunjukkan nilai $\mathrm{p}(0,018)<\mathrm{p}$ value $(0,05)$ berarti ada hubungan pengetahuan ibu dengan pertumbuhan pada balita.

Anak tidak hanya bertambah besar secara fisik, melainkan juga ukuran dan struktur organ-organ tubuh dan otak. Sebagai contoh, hasil dari pertumbuhan otak adalah anak mempunyai kapasitas lebih besar untuk belajar, mengingat, dan mempergunakan akalnya. Jadi anak tumbuh baik secara fisik maupun mental. Pertumbuhan fisik dapat dinilai dengan ukuran berat (gram, pound, kilogram), ukuran panjang (centimeter, meter) umur tulang, dan tanda-tanda seks sekunder (Soetjoningsih, 2013).

Asumsi peneliti, adanya hubungan antara pengetahuan dengan pertumbuhan balita dikerenakan banyak dari responden memiliki pengetahuan yang cukup sehingga ibu tau bagaimana cara agar anak mau makan sehingga pertumbuhan berat badan anak meningkat sesuai dengan umur. Pengetahuan cukup didukung oleh tingkat pendidikan responden yang mayoritas menengah, dengan pendidikan menengah responden sudah mendapatkan informasiinformasi mengenai kesehatan. Selain itu, juga dipengaruhi oleh pekerjaan ibu yang mayoritas hanya sebagai IRT sehingga dengan mudah dapat mengasuh serta memantau petumbuhan anak.

Hubungan Pengetahuan Ibu Dengan Perkembangan Balita : Dari haris penelitian, mayoritas responden memiliki balita dengan perkembangan tidak terhambat sebanyak 195 responden $(96,5 \%)$, yang terdiri dari responden yang memiliki pengetahuan baik 46 responden $(22,5 \%)$, pengetahuan cukup 115 responden $(57 \%)$ dan pengetahuan kurang 34 responden $(17 \%)$.

Dari hasil uji chi square dengan tingkat kepercayaan 95\% $(\alpha=0,05)$ hasil perhitungan menunjukkan nilai $\mathrm{p}(0,230)>\mathrm{p}$ value $(0,05)$ berarti tidak ada hubungan antara pengetahuan ibu dengan perkembangan pada balita. 
Journal of Healthcare Technology and Medicine Vol. 5 No. 2 Oktober 2019

Universitas Ubudiyah Indonesia

e-ISSN : 2615-109X

Keluarga sebagai lingkungan sosial pertama yang dikenal anak memiliki peran penting dalam proses perkembangan sosial anak. Dalam hal ini, perlu diperhatikan keadaan sosioekonomi, tingkat kecerdasan dan pengetahuan, tingkat pendidikan orang tua, pola asuh, serta nutrisi yang diberikan kepada anak (Firdaus, 2018).

Asumsi peneliti, tidak ada hubungan antara pengetahuan ibu dengan perkembangan balita, hal ini disebabkan karena perkembangan anak dipengaruhi oleh lingkungan, pola asuh dari orang tua serta daya tangkap otak dari anak itu sendiri. Dalam penelitian ini lebih banyak ibu yang tidak bekerja sehingga mampu menstimulasi perkembangan anak dengan baik dikarenakan waktu ibu lebih banyak dirumah dibandingkan diluar rumah.

Hubungan Ekonomi Keluarga Dengan Pertumbuhan Balita: hasil penelitian, mayoritas responden memiliki balita dengan pertumbuhan normal sebanyak 193 responden (95,5\%), yang terdiri dari ibu dengan ekonomi keluarga tinggi 49 responden (24\%), ekonomi menengah 143 responden $(71 \%)$ dan ekonomi rendah 1 responden $(0,5 \%)$.

Dari hasil uji chi square dengan tingkat kepercayaan 95\% $(\alpha=0,05)$ hasil perhitungan menunjukkan nilai $\mathrm{p}(0,010)<\mathrm{p}$ value $(0,05)$ berarti ada hubungan antara ekonomi dengan pertumbuhan balita.

Pemberian pola asuh pemenuhan nutrisi dapat memberikan dampak pada pertumbuhan anak. Orang tua dapat dikatakan melakukan pola asuh yang baik jika keluarga dapat mengenal dan memenuhi kebutuhan gizi balita. Hal ini berkaitan dengan pekerjaan orang tua. Berdasarkan pekerjaan orang tua terutama ibu akan mempunyai waktu yang lebih sedikit untuk memperhatikan dan mengasuh anaknya. Pada umumnya orang tuanya bekerja akan diasuh oleh nenek, kakak atau sanak saudaranya dan tempat penitipan anak sehingga pengawasan terhadap makanan dan kesehatan anak tidak sebaik jika orang tua tidak bekerja. Dilihat dari sosial ekonomi (pendapatan) bahwa besar kecilnya pendapatan keluarga tidak lepas dari jenis pekerjaan orang tua (Amelia, 2018).

Asumsi peneliti, adanya hubungan ekonomi keluarga dengan pertumbuhan anak dikarenakan mayoritas responden memiliki tingkat ekonomi menengah, dengan demikian jelas terlihat bahwa untuk memenuhi kebutuhan makanan pokok keluarga sudah mampu, sehingga anak akan mendapatkan asupan nutrisi yang cukup pula.

Hubungan Ekonomi Keluarga Dengan Perkembangan Balita : Dari hasil penelitian mayoritas responden memiliki balita dengan perkembangan tidak terhambat sebanyak 195 responden (96,5\%), yang terdiri dari ibu yang memiliki ekonomi tinggi 50 responden (25\%), ekonomi menengah 144 responden (71\%) dan rendah 1 responden $(0,5 \%)$. 
Journal of Healthcare Technology and Medicine Vol. 5 No. 2 Oktober 2019

Universitas Ubudiyah Indonesia

e-ISSN : 2615-109X

Dari hasil uji chi square dengan tingkat kepercayaan 95\% $(\alpha=0,05)$ hasil perhitungan menunjukkan nilai $\mathrm{p}(0,001)<\mathrm{p}$ value $(0,05)$ berarti ada hubungan antara ekonomi dengan perkembangan pada balita.

Perkembangan melibatkan perubahan, yaitu terjadi bersamaan dengan pertumbuhan disertai dengan perubahan fungsi. Misalnya, perkembangan sistem reproduksi disertai dengan perubahan pada organ kelamin. Perubahan-perubahan ini meliputi perubahan ukuran tubuh secara umum, perubahan proporsi tubuh, berubahnya ciri-ciri lama dan timbulnya ciri-ciri baru sebagai tanda kematangan suatuorgan tubuh tertentu (Soetdjoningsih, 2013).

Asumsi peneliti, ada hubungan ekonomi keluarga dengan perkembangan balita dikarekan perkembangan balita didukung oleh pertumbuhan yang normal pada balita. Untuk mendapatkan pertumbuhan yang baik diperlukan ekononomi yang baik pula untuk memenuhi segala kebutuhan nutrisi. Sehingga efek nutrisi yang dikonsumsi anak terlihat pada perkembangan balita, selain itu perkembangan dipengaruhi oleh lingkungan sekitar, pola asuh orang tua serta kecerdasan atau aspek dari cara kerja otak anak.

\section{KESIMPULAN}

Berdasarkan hasil penelitian maka dapat disimpulkan sebagai berikut: ada hubungan yang signifikan antara pengetahuan ibu dengan pertumbuhan balita dan tidak ada hubungan yang signifikan antara status ekonomi dengan pertumbuhan balita di Desa Geudong Geudong Kecamatan Kota Juang Kabupaten Bireuen Tahun 2019, sedangkan ada hubungan yang signifikan antara pengetahuan ibu dan status ekonomi keluarga dengan perkembangan balita di Desa Geudong Geudong Kecamatan Kota Juang Kabupaten Bireuen Tahun 2019.

\section{SARAN}

Diharapkan kepada masyarakat di Wilayah Setempat untuk dapat lebih aktif dalam mengikuti pelayanan pendidikan dan penyuluhan tumbuh kembang balita agar ibu lebih memahami lagi masalah pertumbuhan dan perkambangan yang terjadi pada balita.

\section{DAFTAR PUSTAKA}

Amelia (2018). Hubungan status Gizi Dengan Perkembangan Psikomotorik Pada balita Usia 3-5 Tahun Di Taman Kanak-Kanak (TK) Se-Kelurahan Belian Kecamatan Batam Kota. Jurnal Kedokteran STM : Fakultas Kedokteran Universitas Batam.

Aruni (2016). Konsep tumbuh kembang anak. Jurnal Kebidanan : Universitas Sumatra Utara.

Bakri (2019). Aceh hingga Papua, ini 4 Provinsi dengan UMP 2019 Paling Tinggi. Profil Keuangan : Jakarta. 
Journal of Healthcare Technology and Medicine Vol. 5 No. 2 Oktober 2019

Universitas Ubudiyah Indonesia

e-ISSN : 2615-109X

Hasballah, (2009). Pertumbuhan dan Perkembangan Anak. Banda Aceh.

Hidayat (2009). Ilmu Kesehatan Anak untuk Pendidikan Kebidanan. Salemba Medika, Jakarta.

Iman. M (2015). Panduan Penyusunan Karya Tulis Ilmiah Bidan Kesehatan. Cita Pusaka: Medan.

- (2014). Pengukuran Variabel dengan SPSS. Cita Pusaka: Medan.

Kusuma (2012). Hubungan Antara Tingkat Pengetahuan Ibu Tentang Tumbuh Kembang Anak Dan Perkembangan Motorik Halus Balita Di Wilayah Kerja Puskesmas Penumping Surakarta. Jurnal Kesehatan : Fakultas Kedokteran Universitas Muhammadiyah Surakarta.

Maryunani (2012). Ilmu Kesehatan Anak Dalam Kebidanan. Trans Info Media, Jakarta.

Mulyono (2014). Dukungan Keluarga Dan Sosial Dalam Pertumbuhan dan Perkembangan Personal Sosial, Bahasa Dan Motorik Pada Balita Di Kabupaten Banyumas. Jurnal Kesehatan Masyarakat : Universitas Negeri Semarang.

Notoadmodjo. (2010). Promosi dan Prilaku Kesehatan, Jakarta: Rineka Cipta.

RISKESDAS (2018). Hasil Utama Riset Kesehatan Dasar 2018. Kementrian Kesehatan Republik Indonesia. Jakarta.

Soetjiningsih (2013). Tumbuh Kembang Anak. EGC. Jakarta. 